\title{
MEKANISME KERJA MESIN SHREDDER DAN ANALISIS KEGAGALAN PADA OPERASI PROSES PENGOLAHAN LIMBAH RADIOAKTIF PADAT MATERIAL TERKONTAMINASI
}

\section{WORKING MECHANISM OF SHREDDER MACHINE AND FAILURE ANALYSIS IN THE OPERATION OF RADIOACTIVE WASTE TREATMENT PROCESS CONTAMINATED MATERIALS}

\author{
Ajrieh Setyawan, Hendro, Purwantara \\ ${ }_{1}^{1}$ Pusat Teknologi Limbah Radioaktif - Badan Tenaga Nuklir Nasional \\ Email: ajrieh@batan.go.id
}

diterima: 20 April 2021, diperbaiki : 28 April 2021, disetujui : 30 April 2021

\begin{abstract}
ABSTRAK
MEKANISME KERJA MESIN SHREDDER DAN ANALISIS KEGAGALAN PADA OPERASI PROSES PENGOLAHAN LIMBAH RADIOAKTIF PADAT MATERIAL TERKONTAMINASI. Mesin Shredder merupakan alat pencacah atau penghancur di mana pada penerapannya di Pusat Teknologi Limbah Radioaktif (PTLR) digunakan untuk mengolah limbah radioaktif padat material terkontaminasi yang memiliki dimensi besar seperti jerigen, drum High-density polyethylene (HDPE), drum korosi dan lainnya. Tujuan akhir dari kegiatan ini adalah untuk memberikan informasi terkait Mesin shredder dan mengetahui hubungan antara mekanisme kerja proses pengoperasi mesin shredder, serta analisis kegagalan dalam proses pengolahan limbah radioaktif padat material terkontaminasi. Metode yang digunakan meliputi pengoperasi alat, pengamatan dan analisis kegagalan operasi alat. Hasil kegiatan diperoleh bahwa kapasitas produksi operasi mesin shredder sebesar $1.008 \mathrm{~kg} / \mathrm{jam}$ untuk limbah padat drum HDPE 160 liter. Untuk menjaga agar operasi mesin dapat berjalan dengan baik diperlukan perawatan secara berkala. Analisis kegagalan dalam proses operasi alat shredder dipengaruhi oleh : operator, sistem operasi mesin, metode operasi, dan material bahan yang diolah.
\end{abstract}

Kata kunci: Shredder, Limbah radioaktif padat (HDPE), Analisis Kegagalan

\section{ABSTRACT}

WORKING MECHANISM OF SHREDDER MACHINE AND FAILURE ANALYSIS IN THE OPERATION OF RADIOACTIVE WASTE TREATMENT PROCESS CONTAMINATED MATERIALS. Shredder machine is a shredder or crusher which in its application at the Radioactive Waste Technology Center (PTLR) is used to treat solid radioactive waste of contaminated material which has large dimensions such as jerry cans, High-density polyethylene (HDPE) drums, corrosion drums and others. The final objective of this activity is to provide information related to the shredder machine and to find out the relationship between the working mechanism of the shredder machine operating process, as well as failure analysis in the process of treating solid radioactive waste of contaminated material. The method used includes operating the tool, observing and analyzing the failure of the operation of the tool. The results showed that the production capacity of the shredder machine operation was $1,008 \mathrm{~kg} /$ hour for 160 liter HDPE drum solid waste. To keep the machine operating properly, periodic maintenance is required. The failure analysis in the shredder tool operation process is influenced by: the operator, the machine operating system, the method of operation, and the material being processed.

Keywords: Shredder, Solid radioactive waste (HDPE), Failure Analysis. 


\section{PENDAHULUAN}

usat Teknologi Limbah Radioaktif (PTLR) merupakan pusat di bawah Badan Tenaga Nuklir Nasional (BATAN) yang mempunyai tugas melaksanakan pengelolaan limbah radioaktif di seluruh Indonesia. Pemanfaatan teknologi nuklir sudah pasti akan menimbulkan limbah radioaktif. Beberapa contoh limbah radioatif padat meterial terkontaminasi yang memiliki dimensi besar seperti : drum HDPE terkontaminasi, jerigen terkontaminasi, dan bahan material padat terkontaminasi radioaktif lainnya. Mesin shredder atau disebut juga mesin penghancur dapat dijadikan salah satu alat bantu pengolahan limbah radioaktif dalam penanganan awal limbah radioaktif padat terkontaminasi yang memiliki dimensi besar dan tidak bisa ditangani langsung dengan alat pengolahan limbah kompaksi yang dimiliki PTLR. [1].

Prinsip kerja alat shredder yaitu menghancurkan material padat dengan mencacah limbah radioaktif seperti drum HDPE dengan menggunakan dua buah mata pisau pencacah menjadi bagian lebih kecil sehingga dapat masuk kedalam drum 100 liter. Tujuan akhir dari kegiatan ini untuk memberikan informasi proses alat shredder dan mengetahui hubungan antara mekanisme kerja proses pengoperasi mesin shredder, serta analisis kegagalan dalam proses pengolahan limbah radioaktif padat material terkontaminasi.

\section{TEORI}

\section{Mesin Shredder}

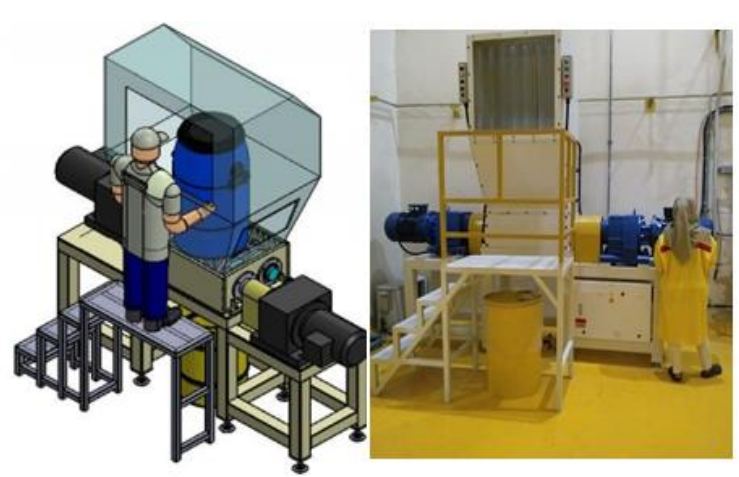

Gambar 1. Mesin Shredder

Desain alat mesin Shredder ditunjukan pada Gambar 1. Mesin mengubah secara mekanik material padat terkontaminasi menjadi bagian potongan kecil. Daya yang dihasilkan oleh motor akan ditranfer menuju gearbox untuk mengubah kecepatan putaran menjadi putaran mata pisau penghancur dengan kecepatan putara $28 \mathrm{rpm}^{[2]}$. Dimensi mesin memiliki ukuran keseluruhan sebagai berikut :

\begin{tabular}{|c|c|c|c|c|}
\hline $\begin{array}{c}\text { Ukuran } \\
\text { mesin }\end{array}$ & $\begin{array}{c}\text { Panjang } \\
\text { (meter) }\end{array}$ & $\begin{array}{c}\text { Lebar } \\
\text { (Meter) }\end{array}$ & $\begin{array}{c}\text { tinggi } \\
\text { (Meter) }\end{array}$ & $\begin{array}{c}\text { Berat } \\
(\mathrm{Kg})\end{array}$ \\
\cline { 2 - 5 } shredder & 2,942 & 1,600 & 2,695 & 1000 \\
\hline
\end{tabular}

\section{Spesifikasi Komponen Mesin Shredder Motor Electric}

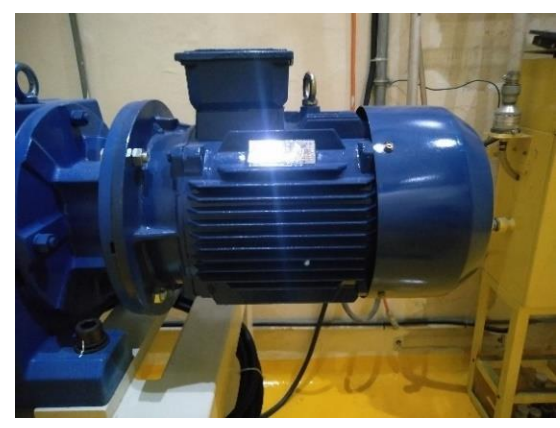

Gambar 2. Motor Electric 
Motor listrik adalah alat untuk mengubah energi listrik menjadi energi mekanik. Mesin Shredder menggunakan arus listrik AC. Spesifikasi dari mesin Shredder ditunjukan pada tabel 1.

Tabel 1. Spesifikasi Mesin Motor

\begin{tabular}{lll}
\multicolumn{3}{c}{ Tabel 1. Spesifikasi Mesin Motor } \\
\hline No & Spesifikasi & Detail \\
\hline 1 & No mesin & DIT 19-024/00- \\
& & 00-00 \\
2 & Main Power & AC 380V \\
3 & Control Power & AC 220V \\
4 & Daya Motor & YUEMA 2 x \\
& & $11 \mathrm{KW}$ \\
5 & Horsepower & $15 \mathrm{Hp}$ \\
6 & Tegangan & $50 \mathrm{~Hz}$ \\
7 & Rpm & 1460 \\
8 & Rasio putaran & $1: 50$ \\
\hline
\end{tabular}

\section{Pisau Penghancur}

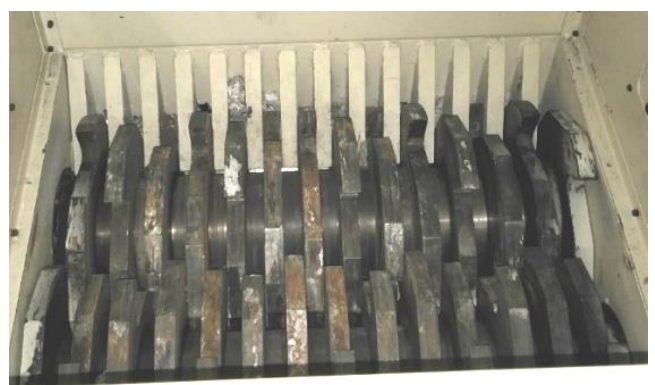

Gambar 3. Pisau Penghancur

Pisau penghancur adalah salah satu komponen yang sangat penting pada alat ini, komponen ini bertugas untuk menghancurkan limbah material padat terkontaminasi. Meterial bahan yang digunakan sebagai pisau penghancur adalah cold work tool steel tepatnya SKD 11 dengan ukuran pisau ditujukan pada tabel 2.
Tabel 2. Spesifikasi Mata Pisau Mesin Shredder

\begin{tabular}{|c|c|c|}
\hline No & Spesifikasi & Detail \\
\hline 1 & $\begin{array}{l}\text { Panjang } \\
\text { Poros Pisau }\end{array}$ & $\begin{array}{l}720 \mathrm{~mm} \text { Bahan } \\
\text { S45C Diameter } \\
100 \mathrm{~mm}\end{array}$ \\
\hline 2 & Bahan & $\begin{array}{l}\text { Bahan S45C } \\
\text { Harden, Tebal } \\
25 \mathrm{~mm}\end{array}$ \\
\hline 3 & Banyak Pisau & $\begin{array}{l}28 \text { Mata pisau } \\
\text { (bagian atas } 14 \\
\text { dan bawah 14) }\end{array}$ \\
\hline 4 & Pisau & $\begin{array}{l}\text { Blade / Pisau : } 3 \\
\text { Mata Pisau }\end{array}$ \\
\hline 5 & $\begin{array}{l}\text { Cutting } \\
\text { Chamber }\end{array}$ & $\begin{array}{l}800 \mathrm{~mm} \times 600 \mathrm{~mm} \text {, } \\
\text { Tebal Plat } 20 \mathrm{~mm}\end{array}$ \\
\hline 6 & $\begin{array}{l}\text { Diameter } \\
\text { Mata pisau }\end{array}$ & $400 \mathrm{~mm}$ \\
\hline 7 & $\begin{array}{l}\text { Gap antar } \\
\text { pisau }\end{array}$ & $40 \mathrm{~mm}$ \\
\hline
\end{tabular}

\section{Control panel}

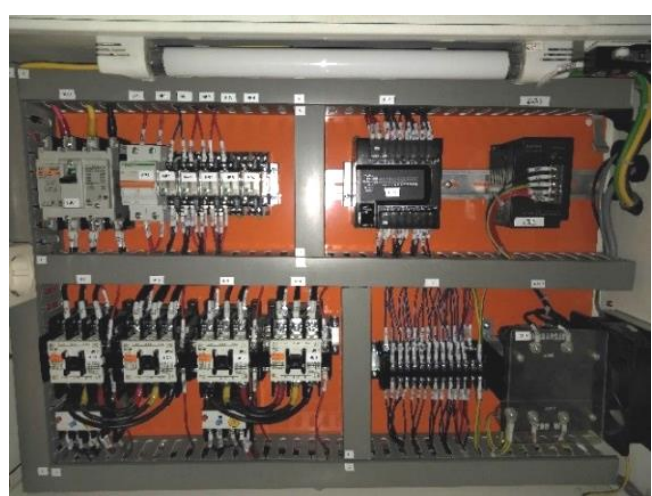

Gambar 4. Control Panel Mesin

Control panel adalah seperangkat rangkaian yang terdiri dari relay, switch, dan sensor yang menunjukan parameter operasi dan pengendalian dari mesin Shredder. Control panel ini sangat penting bagi mesin Shredder yang bertujuan untuk mengetahui kinerja dan keselamatan operasi dari mesin Shredder. Sistem Control Panel mesin Shredder ditunjukan pada Gambar 4. 
Control panel pada mesin Shredder adalah :

a. MCB (miniature cirkuit breaker)

Sebagai sistem proteksi arus berlebih didalam instalasi listrik jika terjadi beban berlebih.

b. MCCB

Sebagai pengaman arus listrik utama atau dapat di guanakan sebagai on/off sistem operasi.

c. RELAY

Sebagai pelindung komponenkomponen sensitif terhadap kelebihan arus yang bekerja dalam pengendalian.

d. PLC (Programeble Logic Control) Untuk mengolah data-data masukan dari sinyal input dan pengendali operasi mesin dan atau motor utama.

e. POWER SUPLAY

Sebagai sumber daya (30kVa, 380volt, 3phase) utama untuk menggerakan mesin.

f. MC (Magnetic contactor)

Sebagai switch pengendali motor utama

g. TRAVO

Sebagai penyalur aliran listrik ke tegangan rendah untuk supply kontrol dari 380 volt ke 24 volt

\section{Exhaust Fan}

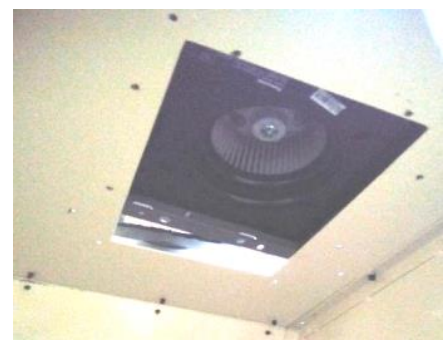

Gambar 5. Exhaust Fan Mesin
Exhaust fan berfungsi untuk menghisap udara kontaminasi hasil operasi mesin di dalam ruang shredder untuk dibuang ke saluran system tata udara fasilitas intalasi pengolahan limbah radioaktif (IPLR). Spesifikasi dari exhaust fan mesin Shredder ditunjukan pada tabel 3.

Tabel 3. Spesifikasi Exhaust Fan

\begin{tabular}{ll}
\hline Model & FV- \\
& 24CDUN \\
\hline Sumber & $220 \mathrm{~V} \sim 50$ \\
Tegangan & $\mathrm{Hz}$ \\
Berat & 3,0 \\
$\begin{array}{l}\text { Produk (kg) } \\
\text { Hembusan }\end{array}$ & 180 \\
Udara (m $\left.{ }^{3} / \mathrm{h}\right)$ & \\
$\begin{array}{l}\text { Arus (A) } \\
\text { Pemakaian }\end{array}$ & 0,086 \\
$\begin{array}{l}\text { Daya (W) } \\
\text { Putaran Per }\end{array}$ & 880 \\
$\begin{array}{l}\text { Menit } \\
\text { min }^{-} \text {1) }\end{array}$ & \\
\hline
\end{tabular}

\section{Panel Operasi}

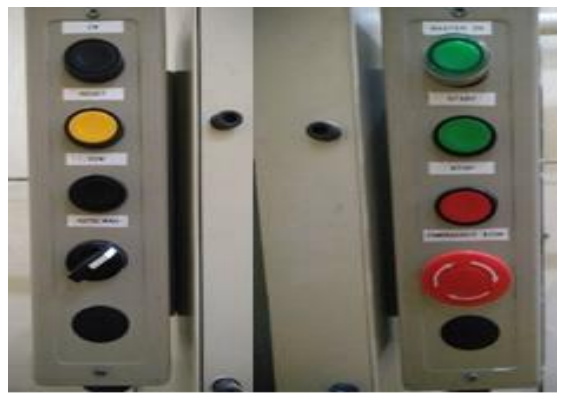

Gambar 6. Panel Operasi

Pengoperasian mesin Shredder dapat dilakukan secara auto maupun manual. Operasi auto atau manual bekerja terkait dengan keselamatan dari alat, yaitu untuk mengantisipasi terhadap berhentinya putaran poros pisau terhadap beban berlebih. Jika putaran pisau berhenti, pada operasi auto maka secara otomatis dalam 3 detik setelah poros berhenti maka sistem akan memutar balik poros secara otomatis. Sedangkan operasi manual jika poros 
pisau terhenti karena beban berlebih maka operator harus menghentikan operasi secara manual dan untuk memutar baliknya dilakukan secara manual dengan menekan tombol counter clockwise (CCW). Panel operasi mesin shredder ditunjukan pada gambar 6 . Tombol fungsi pengoperasian alat ditunjukan pada tabel 4.

Tabel 4. Tombol Pengoperasian Alat

\begin{tabular}{|c|c|}
\hline Nama & Fungsi \\
\hline Tombol On & $\begin{array}{l}\text { Menghidupkan } \\
\text { mesin utama } \\
\text { keseluruhan }\end{array}$ \\
\hline Tombol Start & $\begin{array}{l}\text { Untuk mengaktifkan } \\
\text { start motor berjalan }\end{array}$ \\
\hline Stop & $\begin{array}{l}\text { Untuk } \\
\text { menghentikan } \\
\text { operasi mesin }\end{array}$ \\
\hline $\begin{array}{l}\text { Emergncy } \\
\text { stop }\end{array}$ & $\begin{array}{l}\text { Untuk mematikan } \\
\text { jika terjadi kelainan } \\
\text { operasi pada mesin }\end{array}$ \\
\hline $\begin{array}{l}\text { CW } \\
\text { (Clockwise) }\end{array}$ & $\begin{array}{l}\text { Untuk mengaktifkan } \\
\text { mesin searah jarum } \\
\text { jam }\end{array}$ \\
\hline Reset & $\begin{array}{l}\text { Untuk mematikan } \\
\text { fungsi mesin }\end{array}$ \\
\hline $\begin{array}{l}\text { Forward } \\
\text { (CCW) } \\
\text { (counter } \\
\text { clockwise) }\end{array}$ & $\begin{array}{l}\text { Untuk mengaktifkan } \\
\text { mesin berlawanan } \\
\text { arah jarum jam }\end{array}$ \\
\hline $\begin{array}{l}\text { Ss } \\
\text { auto/manual }\end{array}$ & $\begin{array}{l}\text { Untuk mengatur } \\
\text { mode operasi } \\
\text { manual/auto proses }\end{array}$ \\
\hline
\end{tabular}

\section{METODOLOGI}

\section{Pengoperasi Alat.}

Pengoperasian alat Shredder dikontrol untuk memastikan fungsi alat dapat beroperasi dengan baik dalam mencacah dan atau menghancurkan limbah radioaktif padat material terkontaminasi atau tidak. Selain itu untuk memastikan produk hasil proses dapat dimasukan kedalam drum 100 liter untuk proses pengolahan lebih lanjut.
Pengoperasi alat mesin shredder bekerja berdasarkan urutan :

a. Pemasukan umpan limbah radioaktif padat material terkontaminasi

b. Pencacahan dan penghancuran dalam ruang tertutup

c. Pemasukan dalam drum 100 liter

d. Pengeluaran drum limbah 100 liter hasil produk mesin Shredder

Lingkup metodologi dari kegiatan pengoperasi alat meliputi : pemantauan mekanisme kerja, perawatan mesin dan analisis kegagalan

\section{Analisis Kegagalan.}

Analisis Kegagalan adalah suatu kegiatan yang ditujukan untuk mengetahui penyebab terjadinya kerusakan alat yang bersifat spesifik dari suatu operasi system. Analisis kegagalan bisa berasal dari proses operasi, baik dari operasi alat Shredder maupun cara pengoperasian yang dilakukan oleh operator yang tidak sesuai. Analisis kegagalan bisa dimanfaatkan sebagai umpan balik dalam perbaikan desain dan sebagainya terhadap sistem atau komponen. 


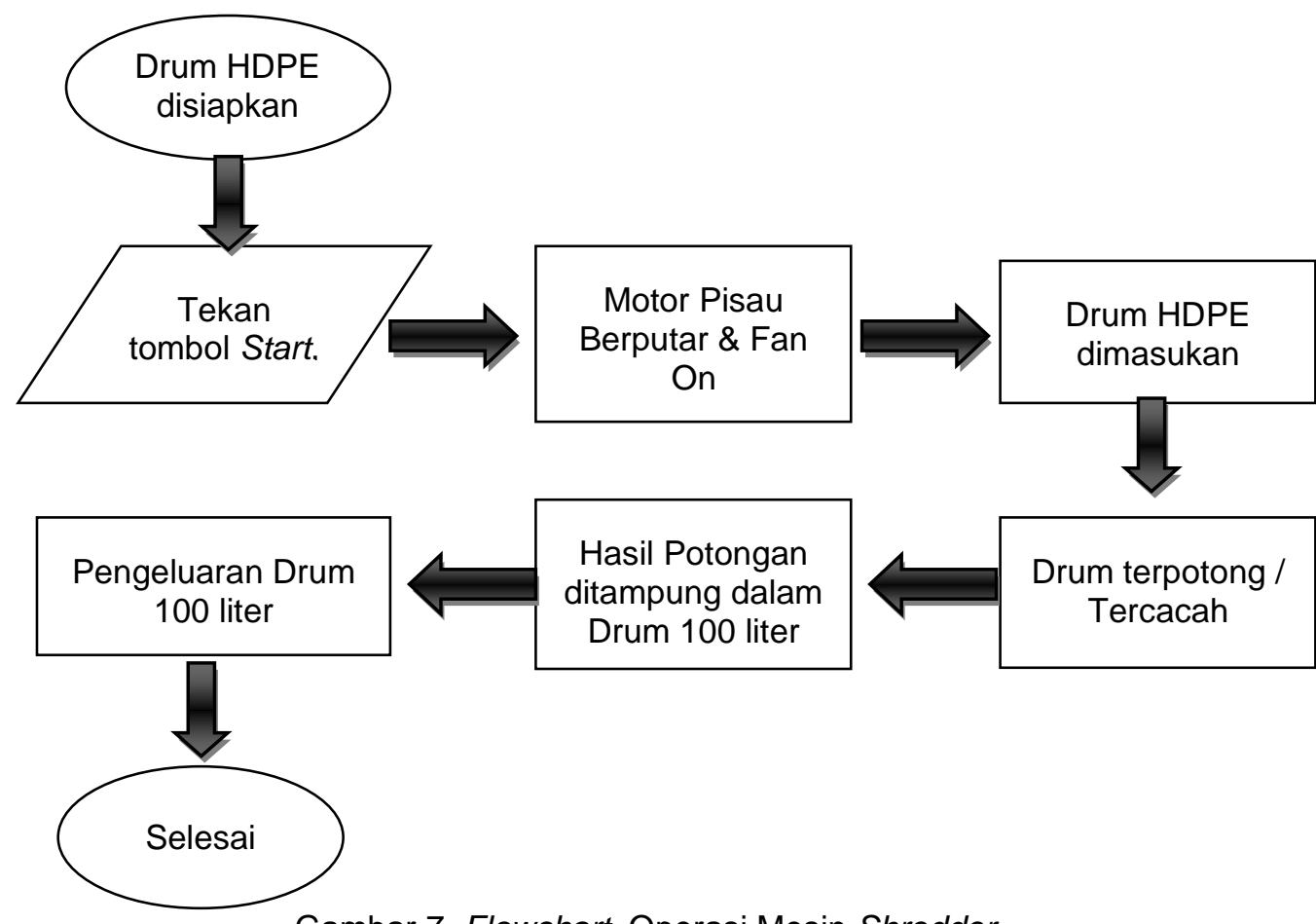

Gambar 7. Flowchart Operasi Mesin Shredder

\section{HASIL DAN PEMBAHASAN}

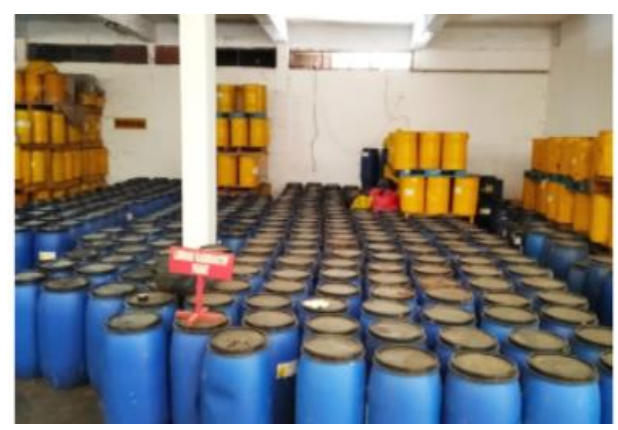

Gambar 8. Limbah tanah terkontaminasi dalam Drum HDPE hasil Clean Up Batan Indah.

Kegiatan Clean Up Batan indah membutuhkan wadah drum HDPE sebanyak 414 drum untuk menampung tanah terkontaminasi. Apabila tanah Clean Up dalam drum HDPE telah dilakukan pengolahan maka wadah drum HDPE tersebut menjadi limbah radioaktif padat terkontaminasi yang harus dilakukan pengolahan lebih lanjut

\section{Data hasil proses pengoprasian mesin shredder}

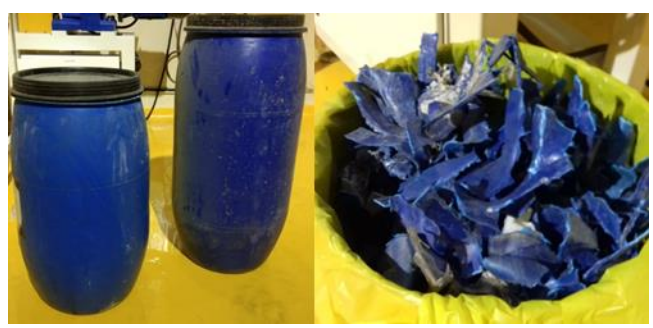

Gambar 9. Drum HDPE sebelum dan setelah diolah dengan mesin pencacah shredder 
Drum HDPE 160 liter di hancurkan dalam mesin Shredder menjadi potongan bagian yang lebih kecil untuk kemudian hasil potongan ditampung dalam drum 100 liter agar dapat diproses menggunakan alat kompaksi yang dimiliki PTLR.

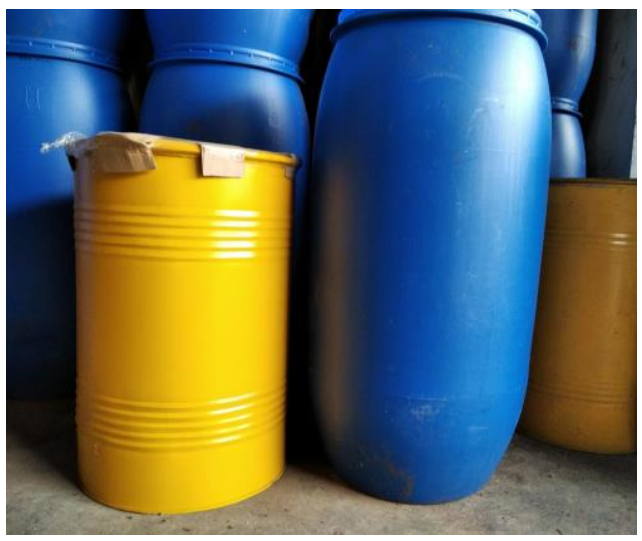

Gambar 10. Perbandingan drum HDPE dan Drum 100 liter

1 drum 100 liter dapat menampung sebanyak 3 buah drum HDPE 160 liter.

Tabel 5. Data proses Pengolahan

Limbah Drum HDPE menggunakan mesin shredder

\begin{tabular}{cccc}
\hline No & $\begin{array}{c}\text { Drum HDPE } \\
\text { 160l }\end{array}$ & $\begin{array}{c}\text { Berat } \\
(\mathrm{Kg})\end{array}$ & $\begin{array}{c}\text { Waktu } \\
\text { (Detik) }\end{array}$ \\
\hline 1 & Sampel 1 & 7 & 25 \\
2 & Sampel 2 & 7 & 25 \\
3 & Sampel 3 & 7 & 25 \\
\hline
\end{tabular}

Perhitungan rata-rata diperoleh data bahwa : Berat kosong 1 buah drum HDPE yaitu $7 \mathrm{~kg}$, waktu yang diperlukan untuk proses penghancuran 1 buah drum HDPE hingga hancur rata-rata yaitu 25 detik. Kapasitas operasi dari mesin shredder dapat dihitung yaitu:

$$
\begin{aligned}
& \mathrm{C}=\frac{w}{t} \times 3600 \text { detik } \\
& \mathrm{C}=\frac{7 \mathrm{Kg}}{25 \mathrm{detik}} \times 3600 \text { detik } \\
& C=1.008 \mathrm{Kg} / \mathrm{jam}
\end{aligned}
$$

Dari perhitungan diperoleh kapasitas proses operasi mesih Shredder adalah $1.008 \mathrm{~kg} / \mathrm{jam}$ (1 ton/jam) untuk drum HDPE 160 liter.

\section{Perawatan Pada Mesin shredder}

Untuk menjaga unjuk kerja fungsi alat agar beroperasi dengan baik maka dilakukan kegiatan perawatan atau yang lebih dikenal dengan kata maintenance. Perawatan adalah suatu usaha yang dilakukan untuk menjaga peralatan atau mesin agar dapat berfungsi dengan baik.

Kinerja mesin shredder akan berada dalam kondisi optimal apabila dilakukan pengoperasian sesuai prosedur, berhati-hati, dilakukan pemeriksaan rutin, pemeliharaan secara berkala, serta dilakukan perawatan dan perbaikan pada bagian mesin yang mengalami kerusakan. Hal yang perlu diperhatikan dalam perawatan dari mesin shredder adalah : 
Tabel 5. Perawatan Mesin Shredder

\begin{tabular}{|c|c|c|c|c|c|}
\hline \multirow{2}{*}{ Jenis Perawatan } & \multicolumn{5}{|c|}{ Waktu Pemeriksaan } \\
\hline & Harian & Mingguan & Bulanan & 6 Bulanan & Tahunan \\
\hline $\begin{array}{l}\text { Pemeriksaan } \\
\text { Kebersihan } \\
\text { Komponen dan } \\
\text { Area Sekitar } \\
\text { Mesin }\end{array}$ & $x$ & & & & \\
\hline $\begin{array}{l}\text { Pengecekan Lampu } \\
\text { Indikator Kontrol } \\
\text { Panel }\end{array}$ & $x$ & & & & \\
\hline $\begin{array}{l}\text { Pemeriksaan } \\
\text { Kondisi Mesin }\end{array}$ & & $x$ & & & \\
\hline $\begin{array}{l}\text { Pemeriksaan } \\
\text { Kebocoran }\end{array}$ & & $\mathrm{x}$ & & & \\
\hline $\begin{array}{l}\text { Pemeriksaan } \\
\text { Saluran Udara } \\
\text { Exhause Fan }\end{array}$ & & & $x$ & & \\
\hline $\begin{array}{l}\text { Pemeriksaan } \\
\text { Tingkat Level Oli }\end{array}$ & & & $x$ & & \\
\hline $\begin{array}{l}\text { Pemeriksaan } \\
\text { Kondisi Oli Motor }\end{array}$ & & & $x$ & & \\
\hline $\begin{array}{l}\text { Pemeriksaan Pisau } \\
\text { Unit }\end{array}$ & & & $\mathrm{x}$ & & \\
\hline $\begin{array}{l}\text { Pemeriksaan } \\
\text { Fungsi Tiap } \\
\text { Komponen }\end{array}$ & & & $x$ & & \\
\hline
\end{tabular}

\section{Analisis Kegagalan}

Analisis Kegagalan pada alat shredder dilakukan untuk mengetahui penyebab terjadinya kerusakan yang bersifat spesifik dari suatu hasil produk penghancuran/pencacahan. Jenis kegagalan pada produk hasil shredder dapat dilihat dari bentuk akhir operasi. Analisis kegagalan bisa berasal dari proses operasi, baik dari : mesin, cara operasi dan material limbah radioaktif padat yang di hancurkan.

Metode Analisis Kegagalan proses operasi mesin shredder digunakanlah metode 4M.

Faktor 4M, yaitu:

1. Man, yaitu faktor dari manusia atau pekerja yang melakukan pengoperasi mesin shredder.

2. Machine, yaitu faktor dari mesin atau alat pendukung untuk mempermudah suatu pekerjaan.

3. Methode, yaitu faktor dari prosedur yang digunakan atau dilakukan

4. Material, yaitu faktor dari bahan material yang diolah.

Solusi untuk menyelesaikannya.

1.

Faktor Man, yaitu dengan memberikan sosialisasi dan pelatihan kepada operator mengenai cara mengoperasikan mesin shredder dengan baik dan benar. 
2. Faktor Machine, yaitu dengan memastikan bahwa komponen mesin dapat berfungsi dengan baik dan benar.

3. Faktor Methode, yaitu dengan membikin prosedur yang baku dalam mengoperasikan mesin shredder dapat berupa SOP, juknis dan atau cara kerja.

4. Faktor Material, yaitu dengan memastikan material limbah radioaktif padat terkontaminasi yang di olah komposisi materialnya merupakan bahan yang dapat di hancurkan / dicacah menggunakan mesin shredder.

\section{KESIMPULAN}

Pengoperasi alat shredder
memiliki kapasitas produksi operasi
sebesar 1.008 kg/jam untuk material
berupa Drum HDPE 160liter. Untuk
menjaga agar operasi mesin dapat
berjalan dengan baik diperlukan
perawatan secara berkala. Analisis
kegagalan dalam proses operasi alat
shredder dipengaruhi oleh : operator,
sistem operasi mesin, metode operasi,
dan material bahan yang akan di
hancurkan / cacah menggunakan mesin
shredder.

\section{DAFTAR PUSTAKA.}

1. Technicatome-BATAN, Solid radioactive Waste treatment, System Note Compaction, 1983

2. PT. Delta Inovasi Teknologi, Assh shredder machine, Depok, Indonesia, 2019

3. KAERI, Operation of Radioactive Waste Treatment Facility, KAERI/MR-455/2006, (2006).

4. IAEA Nuclear Energy Series, 2014, Mobile Processing Systems for
Radioactive Waste Management, IAEA- Vienna

5. K. H. Oma, 1985, Shredder and Incinerator Technology for Treatment of Commercial Transuranic Wastes, Pacific Northwest Laboratory Operated for the U.S. Department of Energy by Battelle Memorial Institute.

6. Undang-undang No 10 Tahun 1997 Tentang Ketenaga Nukliran, (1997)

7. PP 61 Tahun 2013 Tentang Pengelolaan Limbah Radioaktif

8. M. Alma, 2020, Sistem Otomatisasi Exhaust Fan pada alat Shredder di PTLR, Prosiding Seminar SENTEN, BATAN

9. Purwantara, 2020, Rancang Bangun Mesin Shredder, Buletin Limbah, PTLR-BATAN

10. PTLR, 2020, Laporan Kinerja Instansi Pemerintah Tahun 2020, PTLR - BATAN 
Buletin Pengelolaan Reaktor Nuklir

Bulletin of Nuclear Reactor Management

Vol. XVIII, No.1, April 2021:hal. 1-9 